\title{
As raízes jurídicas de Max Weber
}

Gerhard Dilcher

Tradução de Paulo Astor Soethe e Sibele Paulino

Problematizações e problemas

O jurista Max Weber não se constituiu como tema durante muito tempo, sobretudo na Alemanha. Era sabido, naturalmente, que Weber tinha tido formação jurídica. Mas isso foi ofuscado por seu papel como um dos fundadores de uma sociologia científica, como sociólogo da religião, como economista político, como cientista político e, finalmente, como aquele que desenvolveu um método para as ciências sociais a partir de bases teóricas e científicas. Essa perspectiva no enfoque científico conduziu a que sua obra inicial, anterior aos grandes textos metodológicos, recebesse, na virada do século, muito pouca atenção. Isso diz respeito justamente, decerto, aos seus escritos de qualificação na área jurídica, a saber, a tese de doutorado sobre as sociedades comerciais medievais (cf. Weber, 1889; MWG I/1) e a tese de habilitação sobre a história agrária romana (cf. Weber, 1891; MWG I/2). Entretanto, o valor de ambos os trabalhos de Max Weber já se revela no fato de que o primeiro escrito é citado até hoje como obra fundamental do início do direito das sociedades e de sua pesquisa histórica, ao passo que o segundo é atribuído a Max Weber enquanto "historiador da Antiguidade" na tradição de Theodor Mommsen (1817-1903), sem considerar por completo a sua fundamentação jurídica.

Mas, de fato, Max Weber percorreu toda uma carreira jurídica até seu posto como professor (mas não catedrático) na Faculdade de Direito de 
1. As explicaçốes a seguir são expostas mais extensamente na introdução à obra (Dilcher, 2008a) e mais resumidas também em Dilcher (2007a).

2. A carta de Weber na qual ele informa Althoff de sua decisão por Freiburg e também a resposta desolada e compreensiva de Althoff são citadas em Dilcher (2008a, p. 88).
Berlim ${ }^{1}$. Depois da graduação em Heidelberg (1882), Estrasburgo, Berlim e Göttingen, ele prestou o primeiro exame jurídico estatal em 1886; iniciou, então, sua formação como estagiário prático; em 1889, doutourou-se em direito em Berlim e, em 1890, após o término do estágio, passou no segundo exame jurídico estatal (para aspirantes à magistratura); em 1892, habilitouse em Berlim nas áreas de direito romano (o que, na época, abarcava tanto a história do direito como o direito privado vigente) e direito comercial. Antes, ele havia se candidatado em vão ao cargo de síndico na câmara do comércio de Brêmen, o que revela que tinha plenamente em vista uma atividade como jurista praticante. Em Berlim, lecionou sobretudo direito comercial, até que, em 1894, com a nomeação à Universidade de Freiburg, decidiu-se por uma cátedra de economia política e finanças. $\mathrm{O}$ chefe da seção universitária no Ministério da Cultura da Prússia, o renomado e poderoso conselheiro ministerial Althoff, tinha esperanças de poder nomeá-lo para uma cátedra jurídica em uma universidade prussiana, mas acabou por admitir que a nova tarefa em Freiburg correspondia muito mais aos interesses do jovem e promissor docente Max Weber². Essa nomeação foi decisiva para a carreira de Weber nas ciências sociais. Suas cátedras posteriores em Heidelberg (1896) e Munique (1919) foram reestruturadas nesse sentido. Contudo, seu interesse e sua ocupação com questôes da jurisprudência se mantiveram. A prova mais conhecida disso é a sua sociologia do direito, inserida como texto póstumo na obra coligida Wirtschaft und Gesellschaft [Economia e sociedade] (cf. Weber, 1972, cap. VIII, pp. 387-513), ontem e hoje considerada por juristas um texto clássico da sociologia do direito, tanto nos Estados Unidos como na Alemanha. Ela se encontra agora disponível, com aparato editorial crítico, na MWG (cf. MWG i/22-3). Ainda em 1892, no período de sua carreira jurídica, Max Weber também escreveu seu grande estudo empírico sobre a situação dos trabalhadores rurais na Alemanha Oriental, por encargo da Verein für Sozialpolitik [Associação de Política Social] (cf. Weber, 1892), uma vez que, em virtude de sua tese de habilitação, era considerado especialista em questões agrárias (não só romanas).

Nesse sentido, sempre existiu a suposição de que a ligação de enfoques normativos com empíricos, que permeia toda sua obra, tivesse a ver também com a formação jurídica de Weber. Da mesma forma, mostrou-se como a famosa construção metódica de Weber, o tipo ideal, poderia ter sido estimulada pela Allgemeine Staatslehre [Doutrina geral do Estado] do grande jurista Georg Jellinek (cf. Jellinek, 1900), colega de Weber em Heidelberg. Não é atípico, entretanto, que tenha sido inicialmente os norte-americanos 
que, em títulos de artigos, chamaram a atenção para o fundamento jurídico da teoria sociológica de Weber³. É lá que Weber "sobrevive” como sociólogo, graças sobretudo a Talcott Parsons; por intermédio de alunos de Weber, judeus e emigrados - aqui se deve mencionar em primeiro lugar Max Rheinstein ${ }^{4}$-, manteve-se uma tradição continuada de juristas que se ocupam de sua obra, sobretudo com base na sociologia do direito. Mesmo a tese de Weber sobre as sociedades comerciais, com a qual ainda iremos nos ocupar, foi traduzida recentemente para o inglês nos Estados Unidos, para o ensino de sociologia (cf. Weber, 2003). Por outro lado, a redescoberta de Weber na Alemanha após a Segunda Guerra Mundial deveu-se em primeiro lugar ao Weber sociólogo e economista político ${ }^{5}$; depois, desde os anos de 1960, no contexto da confrontação entre neomarxismo e positivismo, ao teórico da ciência e, por fim, ao historiador (cf. Mommsen, 1972; Kocka, 1986). O importante texto de Weber "Die Stadt" [A cidade] fez confluir historiadores da Antiguidade, medievalistas e historiadores do direito ${ }^{6}$. Um interesse intenso por seu cunho jurídico e, com isso, pela obra da fase inicial deu-se finalmente na Itália, onde o jurista Realino Marra formulou de modo bastante incisivo o tema da "formazione giuridica di Max Weber" (cf. Marra, 1992). Mais importante do que a edição da tese de habilitação sobre a história agrária romana - que por sua orientação ampla costuma ser situada no campo da história antiga -, foram as publicações da tese de doutorado sobre as sociedades comerciais medievais (cf. Dilcher, 2008a; Dilcher, 2007a) e, mais recentemente, da sociologia do direito ${ }^{7}$ que conduziram a uma iluminação mais precisa dos primórdios jurídicos de nosso sociólogo e da importância na cunhagem de sua obra como um todo. De fato, o texto completo da tese de doutorado embasava também o processo de habilitação na área de direito comercial e recebeu, a pedido da faculdade berlinense, pareceres de Goldschmidt, professor de Weber, e do famoso historiador do direito Otto Gierke.

Em uma investigação desses nexos, pode-se adentrar em uma dupla problematização: 1) Como foi possível que um aluno que recém concluíra uma formação científica jurídica, como que sem preparação alguma, tenha se tornado um dos principais cofundadores das ciências sociais incipientes, em processo de desenvolvimento? Que pressupostos para tanto eram oferecidos pela jurisprudência alemã na época, e quais focos especiais de interesse foram estabelecidos pelo próprio Weber, como jovem estudante e erudito? 2) Onde é possível reconhecer, na obra tardia de Weber, vestígios de sua conformação jurídica e das matérias jurídicas que o interessavam?
3. "Max Weber as legal historian" (cf. Berman e Reid, 2000) e o título característico "The lawyer as a social thinker" (cf. Turner e Factor, 1994).

4. Max Rheinstein (1899-1977) emigrou em 1933 da Alemanha para os Estados Unidos e trabalhou em Chicago como comparatista jurídico e sociólogo do direito. Em 1954, publicou uma tradução da sociologia do direito de Weber para o inglês.

5. Uma cisão é representada sobretudo pelo Deutscher Soziologentag de 1964, em Heidelberg.

6. O mais das vezes citado na versão de Wirtschaft und Gesellschaft (Weber, 1972, pp. 727-814). Agora em MWG I/22-5. Discussão detalhada do assunto em Meier (1994) e Bruhns e Nippel (2000).

7. Ver a Introdução de Werner Gephart a MWG I/22-3. Antes disso, alguns procedimentos em Breuer e Treiber (1984) e Rehbinder e Tieck (1987). 
A escola histórica do direito no final do século xIx na Alemanha: romanistas, germanistas e o direito comercial

A jurisprudência alemã viveu no século XIX sua fase mais criativa e um grande florescimento, que se irradiou internacionalmente. Ela estava enraizada na concepção humboldtiana da universidade de formação, que foi determinada pelas ciências do espírito, pela filosofia do idealismo alemão e pelas ciências históricas. $\mathrm{O}$ verdadeiro fundador da escola histórica do direito, que desempenhou papel determinante no século XIX, Friedrich Carl von Savigny (cf. Wieacker, 1967; Rückert, 1984), cunhou a partir da universidade reformada de Berlim uma jurisprudência alemã que, sob fundamentos históricos e filosóficos, tomou para si e executou a tarefa de criar, a partir das tradiçôes dispersas e das fontes jurídicas de épocas mais antigas (como sobretudo o direito comum romano e os direitos territorial e urbano alemães anteriores), um direito novo e moderno, direcionado não mais aos variados estamentos, mas sim à igualdade da sociedade civil e à nova ordem econômica. Após as guerras napoleônicas e a dissolução do Sacro Império Romano da Nação Alemã, a Alemanha era constituída de variados principados e cidades livres, frouxamente coligados em uma Liga Alemã. Em virtude dessa situação e das tensões políticas entre Estados monárquicos (como Prússia, Baviera, Württemberg e outros, como o Estado multiétnico da Áustria), de um lado, e o movimento burguês liberal e democrático, de outro, a Alemanha não tinha nem a possibilidade nem a força política para dar forma a uma codificação grande e moderna, sobretudo do direito civil, e implementá-la, tal como havia ocorrido na França sob Napoleão, com o "Code civil" de 1804. Foi só depois da fundação do Império Alemão, em 1871, que se começou a implementar tal legislação, que resultou, em 18961900, na promulgação e entrada em vigor do código civil unificado para todo o Império. Somente o direito comercial tinha podido se antecipar, já que constituía matéria de máxima importância para a Alemanha enquanto espaço econômico. Aqui, graças aos trabalhos preliminares da Liga Alemã, foi possível a entrada em vigor inicialmente de uma ordem cambial, e então, em 1869, do código comercial geral.

Nesse ínterim, a jurisprudência conseguiu criar, por meio do esquadrinhamento histórico e da sistematização teórica - por um lado, do direito romano vigente na Alemanha, baseado no "Corpus iuris civilis" de Justiniano de 534; por outro, das diferentes fontes do direito alemão antigo -, um direito civil que correspondesse, de modo excepcional, às exigências de 
uma moderna sociedade econômica burguesa. Com essa finalidade, a escola histórica do direito desenvolveu uma divisão do trabalho. De um lado, os assim chamados romanistas retrabalharam o direito romano e o consolidaram nos chamados "Digesta" (em alemão: "Pandekten") ${ }^{8}$, que adquiriram quase o estatuto de um texto legal. Para tanto, eles se infiltraram profundamente na história da Antiguidade, para assegurar o fundamento das fontes e para entender os textos historicamente de maneira plena. Assim, Theodor Mommsen, que como jurista organizou de modo decisivo o "Corpus iuris civilis", escreveu, como historiador, uma Römische Geschichte [História romana] que lhe rendeu o prêmio Nobel de Literatura. Ao lado dos romanistas, havia também os germanistas, que, dotados de um conhecimento igualmente profundo da história medieval e moderna, retrabalharam sistemática e historicamente as fontes jurídicas germânicas e alemãs e as sumarizaram em manuais didáticos de "direito privado alemão". Aqui, a ligação entre história geral e história constitucional era especialmente estreita, sustentada também pelo entusiasmo nacional pela história do povo alemão, por cuja unificação política se lutava. Como veremos a seguir, o direito comercial estava, de modo interessante, situado entre as duas tradiçôes dos romanistas e dos germanistas.

\section{A carreira científica de Max Weber como jurista}

Quando Max Weber iniciou seus estudos de direito em 1882, essa jurisprudência da escola histórica estava em pleno florescimento; quando ele se habilitou, em 1892, o esboço para a codificação do direito civil já estava bastante avançado, com o que se delineava, ao mesmo tempo, o fim desse vínculo estreito de jurisprudência histórica e dogmática como parte do direito vigente.

Tanto do lado materno como paterno, Max Weber originava-se de famílias da burguesia, com cultura e posses, e com diversas ligações com personalidades da ciência e da política. Seu próprio pai era jurista, e assim foi natural que também o filho seguisse esse "ganha-pão" burguês. A ampla fundamentação do estudo de direito em história antiga, medieval e moderna, religião e filosofia, vinha bem ao encontro do interesse de estudantes como Max Weber por uma formação abrangente, ao passo que estudantes voltados apenas ao "ganha-pão" decoravam os "Digesta" e assimilavam a matéria com auxílio do repetidor. Um interesse mais amplo como o de Weber era, sobretudo para uma carreira científica, mesmo na jurisprudência,
8. Esses manuais didáticos resumem o direito romano sistematicamente e são chamados de "Pandekten" ou "Digesta", segundo a parte principal do "Corpus iuris civilis". 
em grande medida um pressuposto. Sobre a base igualmente ampla de uma escola histórica desenvolveu-se, naquela época, a jovem ciência da economia política, e também aqui era natural que a sociologia se estruturasse sobre o fundamento de uma ampla empiria histórica e do conhecimento das formas e estruturas sociais. A história do direito e a história constitucional, tal como ensinadas nas faculdades de direito da época por romanistas, germanistas e mesmo representantes do direito público, conduziam diretamente ao conhecimento de formas e estruturas sociais e históricas. Assim, por exemplo, o professor de direito administrativo Rudolph von Gneist, cujas aulas Weber frequentou em Berlim, ensinava os fundamentos da ideia de autogestão, tendo como modelo a história constitucional inglesa.

Nos currículos que Max Weber precisou anexar para o seu doutoramento e a sua habilitação, ele sempre registra, ao lado de seus mestres jurisconsultos, também os cursos e exercícios práticos nas áreas de história e economia política frequentados nas três universidades que cursou, Heidelberg, Estrasburgo e Berlim. Além disso, sabemos muitos detalhes pelas suas cartas de juventude e pela biografia que lhe dedicou sua esposa e companheira Marianne Weber (cf. Weber, 1926). Cabe destacar aí, ao lado dos cursos e exercícios obrigatórios dos grandes nomes da romanística e da germanística, sobretudo em Heidelberg e Berlim, também o estudo em Estrasburgo com Rudolph Sohm, conhecido especialista em direito canônico, que em sua tese fortemente marcada pelo protestantismo apregoava a incompatibilidade entre a essência do cristianismo e a essência do direito. Isso pode ter oferecido o estímulo para uma sociologia da religião de fundamentação secular, como a de Weber, que desenvolveu a ligação entre protestantismo (calvinista) e a formação do capitalismo.

É digno de nota, a seguir, a escolha de seu orientador de doutorado, Levin Goldschmidt, professor de direito comercial na Universidade de Berlim. Por causa de Goldschmidt, Weber recusa, em uma extensa carta, o conselho de seu professor em Göttingen e amigo paternal, Frensdorff, para escrever uma tese sob sua orientação, provavelmente na área de direito citadino medieval alemão. Trata-se, portanto, de uma decisão muito consciente em favor da pessoa e da área de especialidade de seu professor berlinense.

Levin Goldschmidt (1829-1897) foi, de fato, uma figura peculiar na vida

9. Weyhe (1996) oferece uma biografia detalhada. universitária alemã da época ${ }^{9}$. Originário de uma família de comerciantes judeus da Prússia Oriental, ele jamais abriu mão de sua pertença religiosa, a despeito das desvantagens que isso lhe trouxe no início de sua carreira jurídica. Ele se dedicou à jurisprudência nas universidades de Berlim, Halle 
e Heidelberg (habilitação em 1855), sobretudo ao direito comercial, e foi afinal reconhecido em sua competência singular, ao ser nomeado em 1869 juiz do recém-criado Supremo Tribunal de comércio da Liga Alemã do Norte (então pertencente à Liga Alemã). Em 1875, ele se transferiu para uma cátedra específica de direito comercial na Universidade de Berlim, única desse tipo e criada especialmente para ele. A partir de Berlim, Goldschmidt desenvolveu uma atividade científica que na verdade acabou por fundar o direito comercial como disciplina autônoma: dirigiu a redação da Zeitschrift für das gesamte Handelsrecht [Revista de direito comercial geral], por ele fundada e referência até hoje; para o seu manual de direito comercial ele escreveu uma História universal do direito comercial (cf. Goldschmidt, 1891), não superada até hoje; e impulsionou a pesquisa de modo norteador por meio de trabalhos de referência feitos por seus alunos e doutorandos. Se até então o direito comercial havia sido praticado sobretudo por germanistas com base nas fontes de direito citadino alemão medieval e leis específicas mais recentes, Goldschmidt defendia uma concepção bem mais abrangente. Para ele, o direito comercial estava muito menos condicionado por tradições jurídicas individuais do que pelas necessidades do comércio e, com isso, pela "natureza da coisa". O direito romano não havia constituído um direito comercial propriamente dito; Goldschmidt o entendia, contudo, como imprescindível para o direito comercial, como fundamento do direito contratual. Ele viu o nascimento de um direito comercial propriamente dito no espaço comercial medieval do Mediterrâneo, sobretudo das cidades italianas e espanholas. Ao lado disso, tinha interesse também no espaço do mar do Norte e do mar Báltico, mais determinado pelo direito germânico e dominado sobretudo pela Liga Hanseática alemã. Ele pesquisava sobre isso ou estimulava os trabalhos de seus alunos, que acabavam se tornando referência. Embora houvesse, ao menos parcialmente, algumas regulamentações legais dadas no já mencionado "Código comercial alemão geral" [Allgemeines Deutsches Handelsgesetzbuch], Goldschmidt via como central para o desenvolvimento do direito vigente um esclarecimento histórico maior sobretudo das formas sociais específicas da sociedade em comandita, da sociedade comercial aberta e da sociedade por ações. Nesse sentido, ele era um discípulo fiel da escola histórica do direito, mas superou a separação entre romanistas e germanistas em favor de uma apreciação universal e da derivação do direito menos a partir de tradições jurídicas específicas, como o direito romano e germânico, do que a partir das circunstâncias empíricas do comércio. 
Justamente nesses pontos é que se situa a tese de doutorado cuja elaboração Goldschmidt confiou ao jovem Max Weber, depois que este apresentou com sucesso uma aula em seu seminário. Para tanto, o orientador possibilitou a Weber, assim como a seus outros doutorandos, o uso de sua ampla biblioteca pessoal, na qual se encontravam tanto as edições de fontes de referência como as obras mais antigas e mais recentes de direito comercial. Nisto se revela a eficácia da concepção de Wilhelm von Humboldt, segundo a qual a unidade de docência e pesquisa congrega docentes e estudantes.

\section{Temas e métodos na tese jurídica de Weber: direito e história}

Ante a pergunta sobre a importância das raízes jurídicas de Weber em sua obra como cientista social, vale a pena lançar um olhar mais detalhado na tese de doutorado escrita sob orientação de Goldschmidt e publicada em 1889 (cf. Weber, 1889; MWG I/1). Ela possibilita compreender a concepção de Weber acerca da relação entre desenvolvimento econômico e direito, também entre empiria e normatividade, e ainda sobre a importância da prática jurídica, dos usos jurídicos e da jurisprudência; trata de temas que reencontramos na obra posterior de Max Weber, sobretudo nas grandes sínteses em Economia e sociedade (cf. Weber, 1972). Como Weber enfatiza já nas primeiras linhas, seu trabalho tem abordagem tanto histórica quanto de dogmática jurídica. Em análises acuradas de história do direito ele se confronta com diversos temas: a legislação estatutária medieval das cidades italianas na Idade Média desde o século XII, os contratos sociais, a jurisdição de direito comercial dos grandes tribunais citadinos, e da jurisprudência oriunda da Universidade de Bolonha, com seus pontos altos com os juristas Bartolus e Baldus, na Baixa Idade Média. Weber inclui também as cidades portuárias espanholas importantes como partícipes do comércio mediterrâneo. Às vezes o trabalho parece dispersar-se em investigações individuais detalhadas, mas jamais perde de vista os problemas centrais, tampouco o raciocínio geral. Trata-se da pergunta sobre como teria se consumado, na Idade Média, a conformação (marcante até hoje) da sociedade comercial aberta, por um lado, e da sociedade em comandita, por outro. Isso viria a ocorrer na Idade Média, pois a societas romana não poderia, como uma pura relação interna dos societários, oferecer o fundamento para as sociedades comerciais modernas. Estas atuam para fora, na medida em que: 1) o patrimônio societário autonomiza-se como patrimônio especial; 2) os sócios assumem seus devedores de modo solidário; 3) os societários, quando 
em favor da sociedade, sob a designação de uma firma (enquanto nome da sociedade), agem para fora com responsabilidade jurídica.

Essas conceituações e características claras comprovam Max Weber como jurista, e esse tipo de raciocínio também acompanha, mais tarde, seu trabalho como cientista social. Desde o início Weber distingue - e o faz com muito mais acuidade que seu mestre Goldschmidt - entre os desenvolvimentos históricos do direito e da economia: embora as formas jurídicas com frequência se constituam a partir de necessidades da economia, elas também podem assumir vida própria e ser utilizadas depois para a solução de problemas completamente diferentes. Essa vinculação mútua, de um lado, e autonômica, de outro, entre os diferentes domínios funcionais da sociedade desempenharão papel importante na abordagem sociológica de Weber, e além disso na sua influência sobre o desenvolvimento da sociologia, até a moderna teoria dos sistemas (Talcott Parsons, Niklas Luhmann). A fundamentação teórica para isso já se encontra formulada na introdução de sua tese de doutorado.

Para solucionar a questão de como se constituíram as formas modernas das sociedades comerciais, com o florescimento do comércio marítimo no Mediterrâneo e a formação de formas econômicas do início do capitalismo nas cidades italianas desde o século XII, Weber investiga, em primeiro lugar e sobretudo, Pisa como modelo de cidade voltada ao comércio marítimo, e depois Florença, como modelo de cidade do interior com produção industrial e bancos como suportes do setor financeiro. Ao fazê-lo, Weber chega à conclusão de que as duas cidades desenvolvem formas societárias totalmente diversas. A cidade marítima desenvolve a sociedade em comandita, na qual convergem, de maneira complementar, os diferentes papéis do proprietário e capitão do navio, que realiza o comércio ultramarino, e o do cedente de capital, que fica em casa mas provisiona (commenda) o navio com mercadorias. No âmbito da relação societária ocorre, então, ao final, uma repartição dos ganhos, sem que as três características da sociedade comercial aberta, acima expostos, desempenhem papel algum. Em Florença, por outro lado, os produtores e os comerciantes vinculam-se entre si interna e externamente com iguais direitos, de modo a constituir uma sociedade que controla tanto a produção como a venda. Este, para Weber, é o fundamento da sociedade comercial aberta, já que apresenta as três características acima expostas. É por isso que Weber não considera as formas da sociedade comercial aberta e da sociedade em comandita como variações de uma forma societária, mas essencial e historicamente distintas. 
Isso também tem consequências para o direito vigente, que contudo Weber não desenvolve em detalhe.

Weber acompanha historicamente de modo mais aprofundado sobretudo a origem da sociedade comercial aberta. Ele considera que a origem das cooperativas de produção na comunidade familiar está sobretudo na comunidade de irmãos herdeiros com partes iguais, proveniente do direito germânico (langobardo). Elas permanecem em uma comunidade de herdeiros "em única mão", uma figura jurídica que os germanistas desenvolveram a partir de fontes jurídicas germânicas e alemãs. Essas comunidades teriam então incorporado trabalhadores sem vínculo de parentesco; mas junto com a comunidade de irmãos elas formam, como antes, uma comunidade doméstica e de comensais, para a qual se encontra, nas fontes, a designação "stare ad unum panem ed vinum", que evidencia o seu caráter arcaico de comunidade dos que compartilham as refeições. Foi assim que essa forma societária cresceu para além de mera comunidade familiar e de sangue. Essas relações deixam de ser regulamentadas, então, pelo direito consuetudinário e, embora embasadas no costume, são regulamentadas em contratos societários escritos. Nestes é possível regulamentar as questôes importantes e distintivas: a separação do patrimônio societário em relação ao patrimônio pessoal, a responsabilidade comum e a apresentação dos societários externos em uma mesma firma. Essas regras dizem respeito tanto às relações internas dos societários quanto às relações externas da sociedade.

Com essa transição, Max Weber indicou não só a mudança do direito baseado no costume e no uso para o direito escrito, mas também a mudança de formas "sentidas" de "pôr em comunidade" para formas de "pôr em sociedade" baseadas em decisão racional. Já aqui, na tese de doutorado, esses

10. As definições de "pôr em comunidade/comunitarização" ("Vergemeinschaftung") e "pôr em sociedade/socialização" ("Vergesellschaftung") encontram-se em "Soziologischen Grundbegriffen”, $\$$ (cf. Weber, 1972, p. 21). conceitos aparecem da maneira como serão usados posteriormente em suas definições fundamentais em Economia e sociedade ${ }^{10}$. Ao mesmo tempo, também se encontram aqui os enfoques de sua tese do processo de racionalização ocidental (cf. Schluchter, 1998), no qual a juridicização ["Verrechtlichung"] desempenha papel importante; a transição do uso efetivo para a norma jurídica escrita representa essa racionalização.

Ao final de seu trabalho, Weber analisa uma vez mais os diversos fatores que desempenharam um papel quando da constituição da forma jurídica da sociedade comercial no curso da Baixa Idade Média, dos séculos XII ao XV. Tudo começa, para Weber (e nisso ele acompanha seu professor Goldschmidt), com o comportamento efetivo dos participantes, o costume comercial, o uso. Com base nisso é que se constitui a prática jurídica, ini- 
cialmente formulada nos contratos societários, depois na legislação citadina dos estatutos e, por fim, na jurisdição dos tribunais nas grandes cidades comerciais (rotae de Gênova, Lucca, Florença). Weber atribui inicialmente um papel perturbador à doutrina, à jurisprudência das universidades, e com isso à teoria, pois ela estava fixada na figura jurídica da societas romana, que não podia satisfazer as condições "capitalistas" medievais e modernas. Somente quando os juristas eruditos foram incorporados nas tarefas práticas de legislação e jurisdição, nas quais as relações efetivas tinham que ser levadas em conta, é que a doutrina, a jurisprudência e a teoria se tornaram produtivas para o desenvolvimento posterior, pois aqui se revelou a eficácia do "poder elucidador do pensamento jurídico romano". Nessa passagem mostra-se novamente o enfoque da tese weberiana da racionalização, na qual a racionalidade do desenvolvimento do direito no Ocidente (ou seja, na cultura impregnada pelo direito romano) representa um fator essencial. Mas também em sua sociologia do direito mais tardia Weber faz constantes ponderações entre a teoria jurídica, que impulsiona a racionalização com base no direito romano, e a prática enraizada nas relaçôes efetivas. Ao fazê-lo, prevalece sua simpatia pelo direito que se orienta pela prática e se mantém próximo à realidade. Weber encontra isso especialmente - algo também presente na sua sociologia do direito - na história do direito comercial como um todo, até a sua codificação moderna; de maneira ainda mais geral, a orientação prática vale para a Common Law anglo-americana.

Sobre a modelagem histórico-jurídica da formação dos conceitos sociológicos em Weber

Nessa altura mostra-se o quanto figuras básicas do pensamento sociológico posterior de Weber já se encontram em sua tese de doutorado. Tratase sobretudo dos conceitos de comunidade e sociedade ${ }^{11}$ e do paradigma explicativo da racionalização (cf. Idem, ibidem). Como já se sugeriu, para Weber a forma da sociedade comercial moderna, distinta da societas romana, desenvolve-se a partir de formas comunitárias da tradição dos germanos, como as comunidades familiares e domésticas, a coopertativa do trabalho em comum e a comunidade de comensais originária. Em sua acentuação da pertença "sentida", emocional, isso corresponde plenamente ao que Weber denomina depois "pôr em comunidade/comunitarização", que se contrapõe a "pôr em sociedade/socialização", configurada consciente e racionalmente e conduzida pelo interesse. Mas essa oposição já está em sua tese de dou-

11. Conforme a nota anterior. 
12. Ver Weber (1958): sobre o balanço capitalista, p. 184; sobre a calculabilidade, p. 201. Na p. 227: "o processo de dissolução interna do comunismo doméstico pela 'calculabilidade' crescente".

13. Agora na edição MWG I/22-5. $\mathrm{O}$ mais das vezes citado na versão de Wirtschaft und Gesellschaft (cf. Weber, 1972, pp. 727-814).

14. Sobre o tipo da cidade ocidental, ver Weber (1972, pp. 736 e 741 ) e MWG I/22-5, pp. 84 e 100 ss.

15. Weber fala da explosão e da abertura da comunidade comensal ritual dos cristãos judeus em referência a Paulo na Carta aos Gálatas como o "acontecimento de Antióquia” (Weber, 1972, pp. 265 e 745) e vê isso como a fundamentação para a fundação das comunas citadinas da Idade Média. Ver Dilcher (2000).

16. Weber sublinha aqui o juramento de irmanação ou coniuratio, que se tornou importante para a pesquisa da cidade medieval. Ver Weber (1972, pp. 748 ss.) e MWG I/22-5, pp. 124 ss. Sobre o assunto, ver em especial os artigos de Oexle (1994) e Dilcher (2000). torado, quando ele apresenta a celebração do contrato societário segundo regras definidas da partilha dos ganhos e da responsabilidade entre pessoas quaisquer como ato jurídico "voluntário" e conscientemente criado. Depois ele destacará o efeito de racionalização ainda com mais nitidez, ao apontar como o elemento de calculabilidade (isto é, do cálculo exato de acordo com cotas de participação) é acrescido à sociedade pela entrada de capital de quem não pertence à família, e com isso o caráter de comunidade é "dissolvido"12.

Com isso se nota como Max Weber, já em sua primeira obra, tinha em vista o seu grande tema posterior: como explicar o grande processo de racionalização das relações da vida na cultura ocidental, no Ocidente, para o qual o direito racional-formal foi um meio e pelo qual o capitalismo moderno como forma econômica se elevou? Na tese de doutorado ele trata do surgimento das sociedades comerciais como forma de associação na qual capital e força de trabalho podem se unir para a obtenção de ganho. Para ele, a burguesia citadina medieval foi a portadora desse processo. Ele retoma esse ponto em seu estudo histórico-universal sobre "A cidade"13. É notório que ele integra nesse estudo os conhecimentos de sua tese de doutorado sobre as comunas citadinas da Itália setentrional, mas também seus estudos ampliados sobre as cidades do Norte europeu. Não lhe importa mais, agora, a associação estrita das sociedades comerciais, mas sim a formação, como diz ele, de uma burguesia citadina autônoma e autocéfala na antiga pólis e na comuna medieval ${ }^{14}$. Também aqui ele entrelaça elementos da comunitarização emocional - recorrendo até mesmo à comunidade religiosa de comensais da comunhão cristã, que explode os limites das comunidades de sangue e estamento ${ }^{15}$ - com o aspecto da socialização como ato racional e fundado no direito ${ }^{16}$. Aqui também a racionalidade do direito "voluntário" e conscientemente criado desempenha um papel decisivo para a posterior expansão da associação de cidadãos em autogoverno e administração burocrática. Weber toca em outra clave os temas que já havia feito soar em seu escrito de juventude. Do mesmo modo, ele é claramente estimulado, em suas comparações histórico-universais, pela concepção de seu professor Levin Goldschmidt, nomeadamente de uma história universal do direito comercial.

Por fim, gostaria ainda de indicar de que maneira o seu instrumento metodológico-teórico mais importante, o tipo ideal, está prenunciado no primeiro livro de Weber e em seu período de estudante na escola histórica do direito (cf. Marra, 1992; Schiera, 1987). O tipo ideal é para ele - e isso precisa ser sublinhado, contra muitos mal-entendidos - um construto conceitual do cientista, que serve para referir a multiplicidade dos fenômenos 
empíricos a uma problematização e para determinar analiticamente em sua pluralidade ${ }^{17}$. De maneira muito semelhante, Weber empregou em sua tese as características da sociedade comercial moderna já totalmente formada como parâmetro para ordenar em um curso de desenvolvimento as configuraçôes da societas do fim da Antiguidade e da Alta Idade Média (que não encontram correspondência naquela primeira) e distinguir fundamentalmente entre a sociedade comercial aberta e solidária da mera vinculação à entrada de capital de um comanditário. Nisso ele segue o esquema do isolamento de pontos de vista singulares e da generalização unificadora (empregado tanto pela ciência dos "Digesta", nos passos do pensamento sistêmico de Savigny, como, segundo seu modelo, pela germanística no direito privado alemão) com a finalidade de esboçar a partir da pluralidade de regras singulares do direito germânico e romano um sistema de direito civil, que pôde ser então convertido na grande codificação do código civil. Decerto Weber só obtém um fundamento teórico com a recepção da teoria do conhecimento do neokantismo e com o esforço de fundamentar o caráter científico das ciências sociais em seus grandes artigos no início do século $\mathrm{XX}^{18}$. Porém, como ferramenta científica, ele recebeu esse método proveniente da junção da abordagem histórica e da dogmática -, ao qual alude já no início de sua tese de doutorado, da escola histórica do direito, para então utilizá-lo de modo sistemático como fundamentação ao longo de todo o trabalho. Weber precisou apenas fundamentar mais amplamente esse método e expandi-lo para dentro das ciências sociais, com a finalidade de esboçar as grandes conceituações e tipologias que têm até hoje importância capital para a sociologia e a ciência política. Seu tempo de estudante na escola histórica do direito deu-lhe decerto fundamentação para tanto. Weber soube transplantar a fertilidade dessa abordagem histórico-cultural ampla e capaz de associar empiria e normatividade, que havia esgotado suas forças para a jurisprudência, para as ciências sociais recém-fundadas, e com isso tornou-se um de seus grandes mestres.
17. Sobretudo o artigo de Weber de 1904 sobre a "Objetividade" (Weber, 1985, pp. 146-214, sobretudo pp. 190 ss.).

18. Os artigos foram reunidos na Wissenschaftslehre (cf. Weber, 1985). Max Weber, como se sabe, recebeu as ideias da "escola neokantiana do sudoeste alemão" (Wilhelm Windelband, Heinrich Rickert), mas o modo e as incompatibilidades com outras influências em particular (Dilthey, Nietzsche) são temas de debate. 


\section{Resumo}

As raízes jurídicas de Max Weber

$\mathrm{O}$ artigo investiga a formação, a carreira e os trabalhos de Max Weber como jurista, assim como delineia as linhas gerais do impacto e das influências de sua formação jurídica na sua obra em geral. Especial atenção merece sua tese de doutorado sobre as sociedades comerciais na Idade Média, que é apresentada em sua problematização geral e em suas principais ideias. Com isso, procura-se indicar como os problemas tratados por Weber em sua tese de doutorado - sua principal obra jurídica - antecipam temas e problemas que serão desenvolvidos na obra posterior de modo ampliado e aprofundado. Palavras-chave: Max Weber; Max Weber Gesamtausgabe; Direito; Jurisprudência; Sociologia; Economia; Racionalização.

\section{Abstract}

\section{The juridical roots of Max Weber}

The article investigates the formation, career and works of Max Weber as a jurist, and outlines the impact and influences of his legal training on his work in general. Special attention is given to his doctoral thesis on trading societies of the Middle Ages, presenting his overall problematization and his main ideas. The objective is to show how the problems explored by Weber in his doctoral thesis - his main juridical work - anticipate themes and problems developed more widely and deeply in his later work.

Keywords: Max Weber; Max Weber Gesamtausgabe; Law; Jurisprudence; Sociology; Economics; Rationalization. 